\title{
CORRECTION
}

\section{Correction to: EKLT: Asynchronous Photometric Feature Tracking Using Events and Frames}

\author{
Daniel Gehrig ${ }^{1,2}\left([) \cdot\right.$ Henri Rebecq ${ }^{1,2}\left([) \cdot\right.$ Guillermo Gallego $^{1,2}\left([) \cdot\right.$ Davide Scaramuzza $^{1,2}(\mathbb{C}$
}

Published online: 20 September 2019

(c) Springer Science+Business Media, LLC, part of Springer Nature 2019

\section{Correction to: International Journal of Computer Vision https://doi.org/10.1007/s11263-019-01209-w}

The original version of this article was unfortunately omitted to publish the footnote "The best result per row is highlighted in bold" in Table 7. This has been corrected by publishing this erratum. The correct version of Table 7 with the caption has been given below:
Table 7 Performance of the proposed feature tracker using two different types of frames: the DAVIS frames (Brandli et al. 2014), and frames reconstructed using (Scheerlinck et al. 2018)

\begin{tabular}{|c|c|c|c|c|c|}
\hline \multirow[t]{2}{*}{ Scene } & \multirow[t]{2}{*}{ Sequences } & \multicolumn{2}{|c|}{ Track-norm. error (px) } & \multicolumn{2}{|l|}{ Rel. feature age } \\
\hline & & $\begin{array}{l}\text { DAVIS (Bran- } \\
\text { dli et al. 2014) }\end{array}$ & $\begin{array}{l}\text { HF (Scheer- } \\
\text { linck et al. } \\
2018 \text { ) }\end{array}$ & $\begin{array}{l}\text { DAVIS (Bran- } \\
\text { dli et al. 2014) }\end{array}$ & $\begin{array}{l}\text { HF (Scheer- } \\
\text { linck et al. } \\
2018 \text { ) }\end{array}$ \\
\hline \multirow[t]{2}{*}{ Black and White } & shapes_6dof & 0.80 & 1.51 & 0.54 & 0.51 \\
\hline & checkerboard & 1.21 & 1.10 & 0.35 & 0.21 \\
\hline \multirow[t]{3}{*}{ High texture } & poster_6dof & 0.64 & 0.67 & 0.45 & 0.23 \\
\hline & boxes_6dof & 0.72 & 0.74 & 0.54 & 0.41 \\
\hline & bicycles & 0.76 & 0.57 & 0.20 & 0.16 \\
\hline \multirow[t]{3}{*}{ Natural } & pipe_2 & 0.78 & 0.55 & 0.34 & 0.14 \\
\hline & outdoor_day_1 & 0.71 & 0.77 & 0.23 & 0.18 \\
\hline & outdoor_forward_5 & 0.80 & 1.14 & 0.25 & 0.17 \\
\hline
\end{tabular}

The average pixel error and average feature age are reported for all eight test sequences

The best result per row is highlighted in bold

Publisher's Note Springer Nature remains neutral with regard to jurisdictional claims in published maps and institutional affiliations.

The original article can be found online at https://doi.org/10.1007/ s11263-019-01209-w.

Daniel Gehrig

daniel.gehrig18@gmail.com; dgehrig@ifi.uzh.ch

1 Robotics and Perception Group, Department of Informatics, University of Zurich, Zurich, Switzerland

2 Department of Neuroinformatics, University of Zurich and ETH Zurich, Zurich, Switzerland 